\title{
Update on Dietary Compliance, Nutritional Status, and Neuropsychological Functioning in the Chilean Phenylketonuria cohort
}

Journal of Inborn Errors

of Metabolism \& Screening 2021, Volume 9: e20210003

DOI: https://doi.org/10.1590/2326-4594JIEMS-2021-0003

\author{
M.J. Leal-Witt ${ }^{1}$ (D, M.F. Salazar ${ }^{1}$, F. Peñaloza1, G. Castro', \\ V. Hamilton', C. Arias' ${ }^{1}$, P. Peredo', A. Valiente ${ }^{1}$, \\ A. De la Parra', J.F. Cabello' and V. Cornejo'
}

\begin{abstract}
Since 1992, Chile has had a Newborn Screening Program for Phenylketonuria (PKU), which currently has an incidence of 1:18,916 newborns. The objective of the current study was to describe the 2020 follow up of the Chilean PKU cohort. The variables analyzed were: nutritional status, dietary compliance and neuropsychological functioning. We conducted a descriptive crosssectional statistical analysis. The 271 subjects with PKU had an average age of diagnosis of $17 \pm 8$ days and a phenylalanine (Phe) level of $1122 \pm 546$ umol/L. Approximately $80 \%$ of protein requirement came from a protein substitute. For those $<18$ years of age, $80 \%$ had good dietary compliance with Phe level between 120-360 umol/L and those $>18$ years had a median of 522 umol/L $(95 \% \mathrm{Cl} 468$ - 636). Forty-four percent of the active PKU cohort had overweight/obesity. Eighty-five percent of the cohort $>4$ years of age had a normal intelligence quotient (IQ) (score 80-120). We observed a negative correlation ( $\mathrm{p}<0.001 ; 95 \% \mathrm{Cl}$ : -0.5 , -0.2) between IQ score and Phe level. The Chilean protocol and protein substitute subsidy for life, together with the follow-up and continuous education carried out by the clinical team has encouraged compliance.
\end{abstract}

\section{Keywords}

Phenylketonuria, Chilean protocol, Phenylalanine, Newborn Screening.

\section{Introduction}

Hyperphenylalaninemia (HPA) is an autosomal-recessive genetic defect produced by a mutation in chromosome 12q22-q24.1.[1] This chromosome codes for the enzyme phenylalanine hydroxylase (PAH), which catalyzes the chemical conversion reaction from the amino acid phenylalanine (Phe) to tyrosine (Tyr). Thus, Phe begins to accumulate in blood and other tissues, decreasing the synthesis of Tyr.[2] Between 2 to $5 \%$ of these HFAs are produced by the defect of the cofactor system of this PAH enzyme. The worldwide incidence is 1:10,000 newborns (NB), 1:18,916 NB for PKU and 1:10,198 NB for HPA in Chile.[3]

Increased levels of Phe in the blood caused by this metabolic blockage is neurotoxic, producing irreversible damage to the central nervous system, unless diagnosed in the neonatal period and adequate nutritional treatment is started.[4-6] As diagnosis must be early to prevent neurological sequelae, Newborn Screening (NBS) programs have been implemented, which has made it possible to eliminate the intellectual disability caused by PKU.[7-9] In Chile, the NBS for PKU and Congenital
Hypothyroidism $(\mathrm{CH})$ began in 1992 and, to date, has diagnosed more than 500 children with different type of PKU/HPA. To date, 271 children have been diagnosed with PKU who had a Phe value over $360 \mathrm{umol} / \mathrm{L}$ at the time of diagnosis. Children were classified as a classical or variant PKU and entered the followup program of the Institute of Nutrition and Food Technology (INTA) of the University of Chile, the national reference center. Treatment is for life and consists of a Phe-restricted diet that eliminates all foods of animal origin (e.g., meat, dairy products and derivatives, fish and shellfish) and legumes.

\footnotetext{
${ }^{1}$ Universidad de Chile, Instituto de Nutrición y Tecnología de los Alimentos de la Universidad de Chile, Laboratorio de Genética y Enfermedades Metabólicas, Santiago, Chile.
}

Received January 18, 2021, and in revised form April 08, 2021. Accepted for publication April 29, 2021.

\section{Corresponding Author:}

Ma. Jesús Leal-Witt, Email: mj.leal@inta.uchile.cl 
To accomplish energy and protein requirements, a special Protein Substitute (PS) without Phe must be consumed and supplemented with Tyr, vitamins and minerals, which allows for growth and development within normal ranges.[6,10] The Chilean government subsidizes the PS without Phe (Phe-free L-AA mixture) and, since 2017, provides this PS for life. Scientific evidence has shown that maintaining a Phe level between 120 to $360 \mathrm{umol} / \mathrm{L}$ prevents neurological sequelae.[11-13]

The objective of this article was to describe the current situation of critical nutrients and supplementation and dietary compliance, as well as the nutritional status, and the neuropsychological functioning in the Chilean PKU cohort diagnosed by NBS.

\section{Methodology}

We conducted a cross-sectional analytical study of the Chilean cohort with PKU in two hundred seventy-one subjects with PKU diagnosed by NBS.

\section{Inclusion Criteria for the Analysis}

Subjects diagnosed by NBS (Phe $>360 \mathrm{umol} / \mathrm{L}$ at diagnosis) who were in the follow-up program and adhered to the recommended medical-nutritional and biochemical follow-ups according to the INTA follow-up protocol.[6]

\section{Exclusion Criteria for the Analysis}

Subjects with a diagnosis of another associated pathology, and PKU subjects who, in addition to their genetic condition, presented maternal PKU syndrome (PKUm).

\section{Active PKU Group}

Of the total PKU diagnosed by NBS, 205 PKU met the inclusion criteria. Nutritional status, dietary compliance, psychological and biochemical evaluations were evaluated according to the protocol during between January 2019 and July 2020.

\section{Phe and Tyr Levels}

Phe and Tyr levels at diagnosis (umol/L) were determined by tandem mass spectrometry (MS/MS). When Phe level was equal to or above $360 \mathrm{umol} / \mathrm{L}$ and the value of the Phe/Tyr ratio above 3 , the patient entered to the monitoring program at INTA, University of Chile.[2]

\section{Dietary Compliance}

During follow-up, Phe was quantified by fluorometry using a dried blood spot (DBS).[14] Values between 120-240 umol/L and between 120-360 umol/L for Phe were considered adequate for children under and over 2 years of age, respectively. Tyr level must be kept between 44 and $100 \mathrm{umol} / \mathrm{L}$.

\section{Nutritional Status}

Weight $(\mathrm{kg})$ and height $(\mathrm{cm})$ were measured with Seca scale (0.05 kilograms accuracy) and stadiometer $(0.01 \mathrm{~cm}$ margin of error), respectively. Nutritional status in children under 18 years of age was classified using the technical standard for nutritional evaluation used in our country based on the World Health Organization (WHO)[15-18] standards by age: obesity (> 2 standard deviation, SD); overweight (1 to $2 \mathrm{SD}$ ); normal weight (-1 to $1 \mathrm{SD})$; risk of malnutrition (-1 to $-2 \mathrm{SD})$; malnutrition (<2SD). In those over 18 years of age, nutritional status classification was based on Body Mass Index $\left(\mathrm{BMI}\left(\mathrm{kg} / \mathrm{m}^{2}\right)\right.$ and the standards of the Chilean Ministry of Health supported by the WHO age and sex-specific limits.[19]

Classification of height was only applied to individuals under 18 years of age in SD: tall height $(>2 \mathrm{SD})$; tall normal height (1 to 2 $\mathrm{SD})$; normal height (-1 to $1 \mathrm{SD})$; short normal height (-1 to $-2 \mathrm{SD}$ ); short height (<- 2SD), according to the technical standards for nutritional status established by the Chilean Ministry of Health.

\section{Diet Analysis}

A 24-hour dietary recall (24R) was carried out at the nutritional interview and intake was quantified with the amino acid analyzer (AAA) software. Only one $24 \mathrm{R}$ was considered, as our protocol establish for the following up registered in the clinical record. Energy intake (kcal/d) and protein $(\mathrm{g} / \mathrm{d})$ were estimated. In relation to protein intake, the following were considered: PS without Phe (g/d), Phe intake $(\mathrm{mg} / \mathrm{d})$ and Tyr $(\mathrm{mg} / \mathrm{d})$. The percentage of nutritional adequacy of: Calcium (Ca; $\mathrm{mg} / \mathrm{d}$ ), Iron (Fe; mg/d), and Zinc (Zn; mg/d) intake was determined, according to the Recommended Dietary Allowance (RDA)[20], considering 90-110\% acceptable.

\section{Neuropsychological Function}

In children under 3 years of age, psychomotor development was determined using the Bayley Scale of infant and toodler development (Bayley II, Second edition) [21,22], which include a mental development index (MDI) and motor development index (PDI). An MDI and PDI score $>80$ points was classified as normal development. In those over 4 years of age, the Wechsler Scale was used. The Wechsler Preschool and Primary Scale of Intelligence (WPPSI)[23] test was used in the 4-6 year-old group and, for those between 6 and 18 years of age, the Wechsler Intelligence Scale for Children, Revised Third Edition (WISC-R or WISCIII)[24] was used. For adults, greater than 18 years old, Weschler Adult Intelligence Scale (WISC-IV)[25] was used. The results were expressed as is full scale intelectual quotient (FSIQ) of the total scale according to the score obtained for each individual. Intelectual quotient (IQ) was classified as normal if between 80 and 120 points. 


\section{Statistical Analysis}

A descriptive analysis of the variables was carried out, in which the distribution for each variable was determined using the Shapiro-Wilk test. Depending on the distribution, the mean or median was calculated, and, depending on the statistic used, the SD or the $95 \%$ confidence interval (CI) reported. Spearman's correlation was performed to verify the association of variables. A p-value $<0.05$ was considered statistically significant. Microsoft Excel 16.34 and JMP ${ }^{\circledR}$ 14.2.0 were used for analyses.

\section{Ethical Committee Reports}

Medical records review and the use of data from the subjects with active PKU for the analysis of this update was approved by the Ethics Committee of INTA (Approved 20th January).

\section{Results}

In the 271 subjects diagnosed with PKU since 1992 who required treatment and entered the follow-up program at INTA, 126 (46\%) were female. The average age of diagnosis was at $17 \pm 8$ days, with Phe levels of $1122 \pm 540 \mathrm{umol} / \mathrm{L}$ (95\% CI 1056 - 1182) and Tyr of $71.5 \pm 55 \mathrm{umol} / \mathrm{L}$ (95\% CI 66 - 77). The group was made up of 8 PKU (3\%) less than 1 year old, 24 (9\%) between 1 and 3 years old, 62 (23\%) between 4 and 9 years old, 51 subjects (19\%) between 10 and 14 years, 37 (14\%) between 15 and 17 years old and 89 subjects (33\%) older than 18 years. Because $40 \%$ of the Chilean population lives in the Metropolitan Region, which includes the capital, Santiago, $46 \%$ of the cohort is concentrated in this region.[26]

In the active PKU group ( $\mathrm{n}=205), 4$ subjects $(1 \%)$ were classified as malnourished, 113 (55\%) were classified as normal weight, 48 (24\%) as overweight and 40 (20\%) as obese. The highest percentage of overweight and obesity was found in participants between 1 and 9 years, reaching up to $50 \%$ in these groups. With respect to height, $2 \%$ had short stature ( 2 subjects aged $1-3$ years and one aged 4-9 years).
For diet, considering the median intake all age groups complied with the protein recommendation according to the Chilean protocol.[5,6] When quantifying protein contribution from the PS without Phe, it was observed that, in children under 1 year of age, $61 \%$ of total proteins came from PS without Phe and, in older age groups, the percentage fluctuated between 75 and $88 \%$ (Figure 1). Fifty-one subjects were being supplemented with L-Tyr, due to the fact that they maintained a value of this amino acid under $44 \mathrm{umol} / \mathrm{L}$. The supplementation delivered was between 100 and $1500 \mathrm{mg}$ of L-Tyr; 35\% of subjects were between 1-3 years, $38 \%$ between $4-9,31 \%$ between $10-14$, 19\% between $15-17$ and $6 \%$ were older than 18 years of age. A median value of $55 \mathrm{umol} / \mathrm{L}$ (range: $16.5 \mathrm{umol} / \mathrm{L}$ - $138.6 \mathrm{umol} / \mathrm{L}$ ) was observed for plasma Tyr value (MS/MS) at the time of supplementation. All PKU patients were observed to have adequate (90 to $110 \%$ ) intake of $\mathrm{Ca}, \mathrm{Fe}$ and $\mathrm{Zn}[20]$ (Table 1).

According to the Phe values found, it was observed that the cohort maintained Phe levels within levels recommended for their age (Figure 2). We observed that the group between 2 and 14 years of age maintained good metabolic control during the evaluation period (Figure 2). However, for those 15 to 17 years of age, median Phe value was $354 \mathrm{umol} / \mathrm{L}$ (95\% CI 336 - 484) and $522 \mathrm{umol} / \mathrm{L}(95 \% \mathrm{CI} 468$ - 636) in those over 18 years. It is important to point out that $70 \%$ and $57 \%$, respectively of these age groups keep their controls up to date (Figure 2).

In this analysis, the metabolic status of the group of women of childbearing age with PKU was also assessed. Those between 10 and 14,15 to 17 , and $>18$ years of age had median Phe levels of: $306 \mathrm{umol} / \mathrm{L}$ (95\% CI 270 - 384), $342 \mathrm{umol} / \mathrm{L}$ (95\% CI 270 384) and 492 umol/L (95\% CI 390 - 576), respectively. Among women between 10 and 18 years of age $(n=56), 44 \%$ had a Phe value above $360 \mathrm{umol} / \mathrm{L}$ and $62 \%$ among women over 18 years of age (Figure 3.B). No significant difference was found when comparing median Phe level by sex, even after separating by age group (Figure 3.A, 3.B).

Table 1. Intake analysis for the active PKU group, separated by age group.

\begin{tabular}{|c|c|c|c|c|c|c|}
\hline & $0-1$ years & $1-3$ years & 4-9 years & $10-14$ years & $15-17$ years & $\geq 18$ years \\
\hline Calories per kg of weight (kcal/kg) & $\begin{array}{c}110 \\
(87-140)\end{array}$ & $\begin{array}{c}78 \\
(68-94)\end{array}$ & $\begin{array}{c}50 \\
(47-56)\end{array}$ & $\begin{array}{c}34 \\
(32-39)\end{array}$ & $\begin{array}{c}29 \\
(26-37)\end{array}$ & $\begin{array}{c}25 \\
(24-29)\end{array}$ \\
\hline Protein intake (g/kg weight) & $\begin{array}{c}2.6 \\
(2.2-2.8)\end{array}$ & $\begin{array}{c}2.6 \\
(2.4-2.7)\end{array}$ & $\begin{array}{c}2.0 \\
(1.9-2.2)\end{array}$ & $\begin{array}{c}1.6 \\
(1.6-1.7)\end{array}$ & $\begin{array}{c}1.5 \\
(1.4-1.6)\end{array}$ & $\begin{array}{c}1.4 \\
(1.3-1.5)\end{array}$ \\
\hline Phe intake (mg/day) & $\begin{array}{c}312 \\
(181-431)\end{array}$ & $\begin{array}{c}274 \\
(245-441)\end{array}$ & $\begin{array}{c}410 \\
(408-564)\end{array}$ & $\begin{array}{c}408 \\
(373-569)\end{array}$ & $\begin{array}{c}491 \\
(370-911)\end{array}$ & $\begin{array}{c}457 \\
(498-813)\end{array}$ \\
\hline Calcium, \% adequacy & $\begin{array}{c}231 \\
(180-318)\end{array}$ & $\begin{array}{c}127 \\
(118-144)\end{array}$ & $\begin{array}{c}143 \\
(130-155)\end{array}$ & $\begin{array}{c}161 \\
(156-190)\end{array}$ & $\begin{array}{c}189 \\
(166-201)\end{array}$ & $\begin{array}{c}217 \\
(213-275)\end{array}$ \\
\hline Iron, \% adequacy & $\begin{array}{c}106 \\
(83-129)\end{array}$ & $\begin{array}{c}132 \\
(130-195)\end{array}$ & $\begin{array}{c}214 \\
(207-245)\end{array}$ & $\begin{array}{c}215 \\
(216-296)\end{array}$ & $\begin{array}{c}215 \\
(185-259)\end{array}$ & $\begin{array}{c}241 \\
(231-312)\end{array}$ \\
\hline Zinc, \% adequacy & $\begin{array}{c}279 \\
(199-368)\end{array}$ & $\begin{array}{c}170 \\
(193-348)\end{array}$ & $\begin{array}{c}188 \\
(201-269)\end{array}$ & $\begin{array}{c}205 \\
(204-272)\end{array}$ & $\begin{array}{c}228 \\
(198-269)\end{array}$ & $\begin{array}{c}211 \\
(190-250)\end{array}$ \\
\hline
\end{tabular}

24-hour dietary recall provided in the nutritional consultation for each individual. Calculation performed by Aminoacid Analyzer software (AAA). Records of 185 subjects were obtained.

All variables had a non-normal distribution. Values represented by the median $(95 \% \mathrm{Cl})$. 


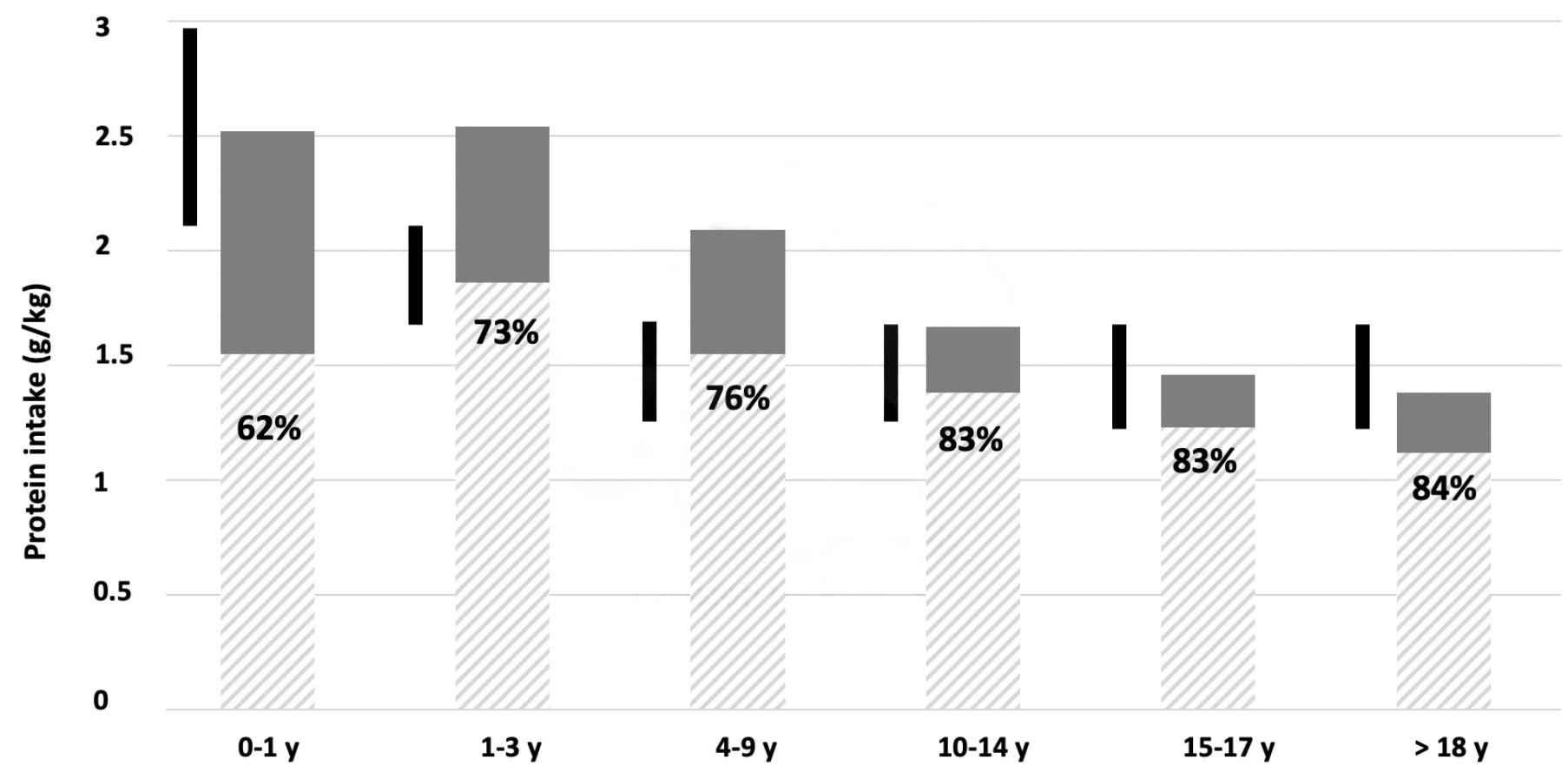

Figure 1. Protein intake by group. Black lines represent protein recommendations per protocol by age group. Each column represents $100 \%$ of average protein intake group; shaded regions represent the percentage of the total intake from the protein substitute.

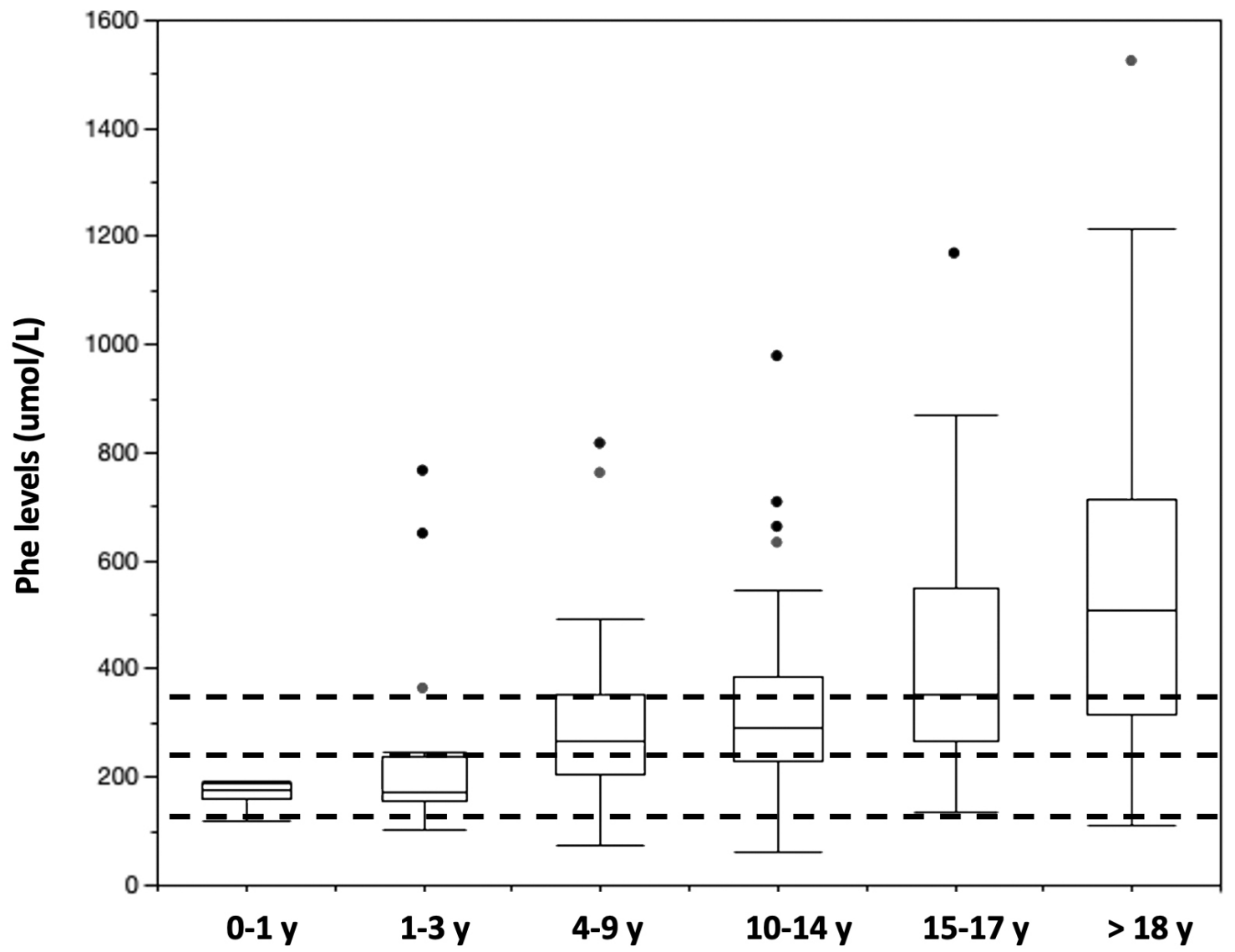

Figure 2. Boxplots of Phe values in blood by age group. Each boxplot represent the 25,50 and 75 quartiles of Phe level for each group. Dotted lines represent permitted upper and lower Phe levels permitted according to the protocol (<2y: $120-240 \mathrm{umol} / \mathrm{L} ;>2 \mathrm{y}$ : $120-360$ umol/L) 
Considering that the evaluation of neuropsychological function is one of the most important variables in long-term follow-up among people with $\mathrm{PKU}$, it was observed that children aged 1 to 3 years had an average MDI of $82 \pm 16$ points. For IQ, the 4-9-year-old group had an average an FSIQ of 93.9 \pm 12.3 points; $96.4 \pm 13.5$ points among subjects aged $10-14$

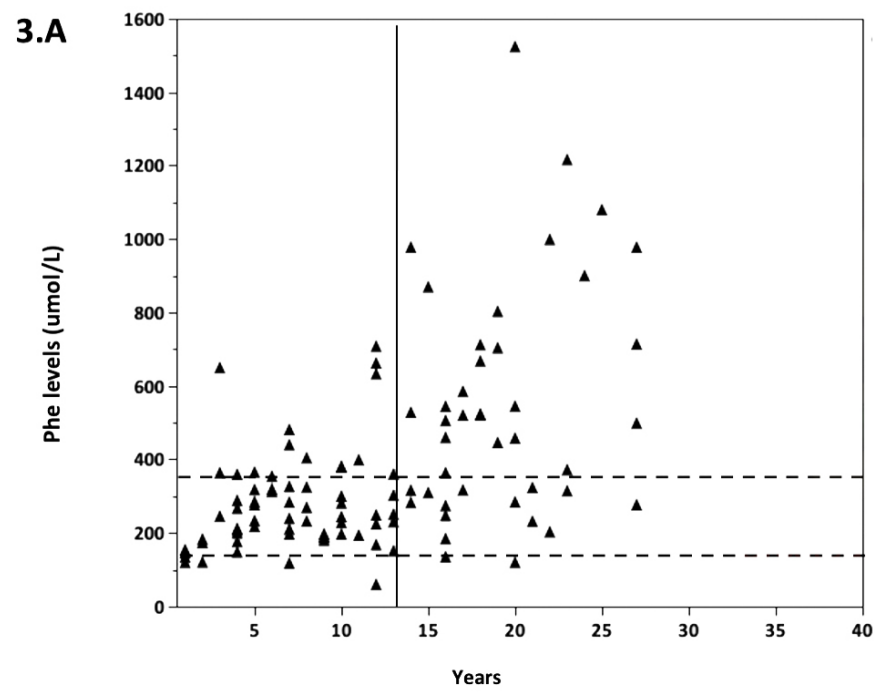

years; $88.9 \pm 17.6$ for those between $15-17$ years; and $88.6 \pm$ 13.2 points for those over 18 years. The FSIQ obtained in the last psychometric evaluation was negatively and significantly correlated with average Phe level for the period considered for the analysis (Rho $=-0.311$; p-value $<0.001 ; 95 \%$ CI: $-0.5 ;-0.2$; $\mathrm{n}=154)$ (Figure 4).

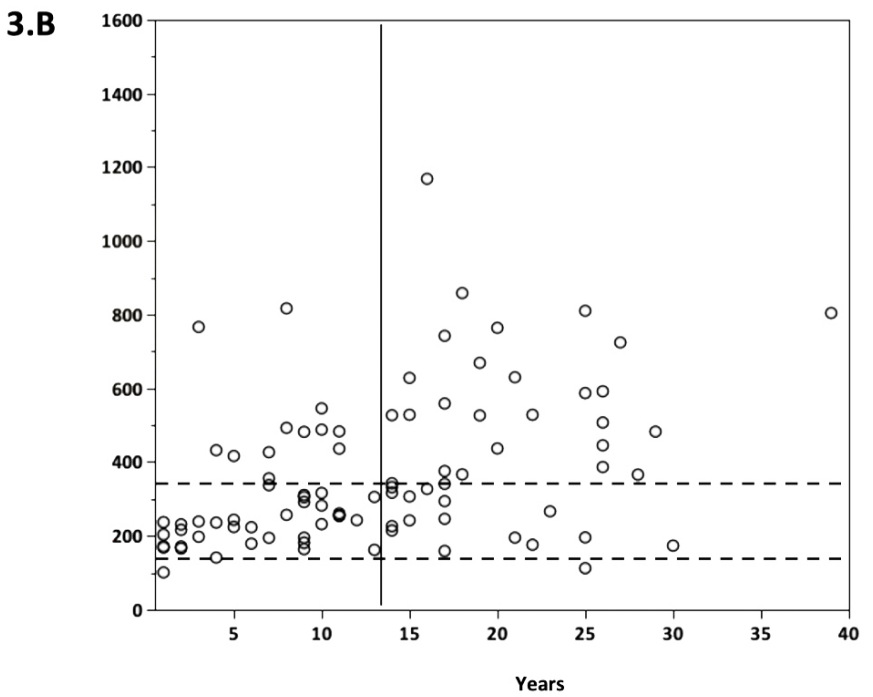

Figure 3. Dispersion graph of Phe level by sex. 3A. Black triangles represent male subjects. $3 \mathrm{~B}$. White circles represent female subjects. The vertical line separates $<14$ years of age and $\geq 14$ years. Permitted levels of Phe according to the protocol $(<2$ : $120-240$ umol/L; $>2 y: 120-360$ $\mathrm{umol} / \mathrm{L}$ ) is represented between the dotted lines.

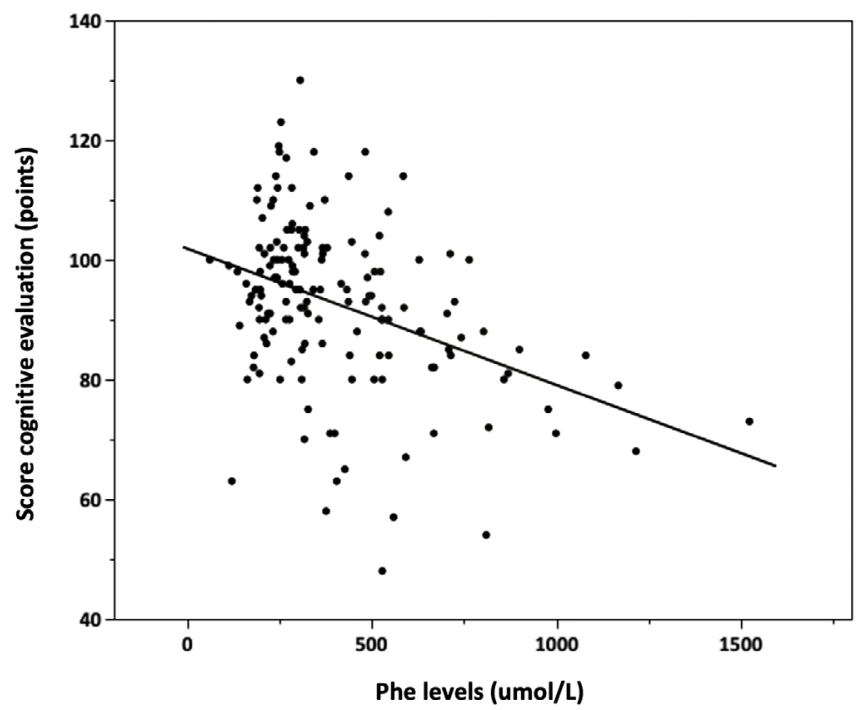

Figure 4. Spearman's correlation between average Phe level (mg/ $\mathrm{dL}$ ) calculated for each subject with the score obtained from the last evaluation of neuropsychological functioning, considering subjects over 4 years of age and who had both values $(n=154)$. Rho: $-0,31: p$ $<0.001$; $95 \% \mathrm{Cl}:-0.5,-0.2$.

\section{Discussion}

The national NBS programs for PKU and $\mathrm{CH}$ in Chile has been a pioneer, jointly with Cuba, Costa Rica and Uruguay have pioneered the implementation of this type of programs in Latin America for the last 28 years. [27] Currently there are 9 countries in the region with a similar program underway, who together developed of the Latin American Consensus Guide for Newborn Screening of PKU in 2016.[28]

Since the last published update of the Chilean PKU cohort in 2010[3], we observed that the age of diagnosis has decreased from $20 \pm 8$ days to $17 \pm 8$ days of age, with treatment starting before one month of life. In relation to Phe levels at the time of diagnosis, in 2010, Phe level was on average $1194 \pm 540 \mathrm{umol} / \mathrm{L}$. In the current study, we observed levels of $1122 \pm 540 \mathrm{umol} / \mathrm{L}$ (95\% CI: 1056 - 1182), which allows us to confirm that after 10 years of development, the NBS maintains stable and a good coverage in Chile.

The current population was distributed across age groups. We observed that the highest percentage of children is found in the group between 4 and 9 years of age (23\%) and in the group over $18(33 \%)$. 
In 2017, after more than 30 years of experience in the treatment of PKU, the Chilean protocol for the follow-up for this population was published, establishing $360 \mathrm{umol} / \mathrm{L}$ as the Phe level to start a Phe-restricted diet. Values of Phe permitted during follow-up and the critical nutrient requirements in different age groups, according to international recommendations were also determined.[6]

Of the 271 subjects diagnosed with PKU, 76\% (205 subjects) belonged to the active PKU in the period considered for the current analysis. In our active PKU group, $44 \%$ were found to be either overweight or obese. In 2015, an abstract was presented at the Latin American Society for Inborn Errors of Metabolism and Neonatal Screening (SLEIMPN) conference, where the nutritional status of the PKU cohort in 2015 was reported. At that time, $35 \%$ of the cohort had overweight or obesity. [29] In the current study, conducted 5 years later, we observed that overweight and obesity increased by $9 \%$. This result is in accordance with the current obesity pandemic in Chile. In the most recent reports of the National Health Survey in Chile carried out in 2017 and 2018, it was reported that $74.2 \%$ of the adult population over 18 years of age and $52 \%$ of schoolchildren under 15 years of age were overweight or obese.[30,31] Scientific evidence has indicated that PKU patients, compared to the nonPKU population, have a prevalence ratio of 2.06 for obesity.[32] Therefore, especially in the pediatric population, it should be a top priority to take these data into account to avoid the development of obesity at all life stages and the risk factors for triggering associated pathologies, such as cardiovascular diseases, insulin resistance, or Diabetes Mellitus, among others. The importance of conducting nutrition education and incorporating healthy lifestyles in people with PKU is emphasized to prevent diseases associated with excess malnutrition, which could affect health and long-term quality of life.[33,34]

Regarding protein, Phe, Tyr and micronutrient intake, the recommendations of the Chilean protocol[6] and the protocol published by Singh et al.[5] were followed. We know that meeting protein requirements from natural foods is not possible, and, thus, the PS without Phe is essential to achieve growth and development within the normal range. Prior to 2017, the Chilean government subsidized the PS without Phe until 18 years of age, but now the subsidy is for life. In our cohort, among those over 18 years of age, we found that $85 \%$ of the total protein ingested comes from the PS without Phe, becoming an essential product to achieve satiety and maintain good metabolic control. In children with PKU under one year of age, this percentage is $60 \%$, because, during this period of accelerated growth, the Phe requirements are higher, and these requirements are mainly covered by intact protein from breast milk or infant formula.[9,35] The PS without Phe not only provides quality protein, but also covers the recommendations of Tyr, vitamins and minerals. $[10,36,37]$ In our active $\mathrm{PKU}$ cohort, when comparing $\mathrm{Ca}, \mathrm{Fe}$ and $\mathrm{Zn}$ intake with international recommendations, we observed that all received contributions over $110 \%$ adequacy according to RDA.
The use of adjuvant treatments in PKU with low or no adherence to dietary treatment is recommended. However, we must point out that in Chile this cannot be applied, because the government does not cover the costs of $\mathrm{BH} 4$, Large neutral amino acids (LNAA), Glycomacropeptide (GMP). The Chilean protocol considers good metabolic control when patients under 2 years of age with PKU have Phe values between $120-240$ $\mathrm{umol} / \mathrm{L}$. This more restricted range is due to the fact that this group has a greater metabolic fluctuation due to the mandatory vaccination program in Chile and/or intercurrent infections, which induce catabolism and increase Phe concentration. The period under 2 years of age is considered a critical period for brain development, thus lower concentrations of Phe allows a better control over increases. For PKU patients older than 2 years of age, good metabolic control is defined as Phe values between 120 - $360 \mathrm{umol} / \mathrm{L}$.

Scientific evidence highlights that in adolescence and adulthood, adherence to treatment decreases with age, which signifies a progressive increases in Phe values and risk of damage to central nervous system. Burton et al. demonstrated in 2002 that $75 \%$ of adolescents had high Phe levels and more than $80 \%$ had low adherence or had abandoned treatment in adulthood. [38] In 2017, in a survey carried out among approximately half of the PKU patients seen in clinics in the USA, it was observed that more than $60 \%$ of adolescents aged 13 to 17 did not comply with recommendations given, which translated into Phe values over those recommended.[39] In our cohort, considering the group between 10 to 17 years of age, $70 \%$ of this group maintained their metabolic control below $360 \mathrm{umol} / \mathrm{L}$.

In the European PKU cohort, those over 18 years of age had an average Phe level of $960 \mathrm{umol} / \mathrm{L}$ with low adherence to the indicated treatment.[40] Among those in our cohort over 18 years of age, we found that $35 \%$ maintained diet compliance with Phe values recommended by the protocols.[5,10,41] The average Phe level in blood was $546 \pm 294 \mathrm{umol} / \mathrm{L}$, which is close to the maximum level allowed by the European protocol.[10,41] However, it is important to remember that before 2017, the subsidy for PS without Phe ended at 18 years of age. Therefore, many of these adult patients with PKU have now resumed nutritional treatment. Since the changes in the policy, dietary compliance has increased from 35 to $55 \%$.

Another important point to discuss is the adherence and good metabolic control that female PKU patients should have, since Phe levels over $360 \mathrm{umol} / \mathrm{L}$ during pregnancy is strongly associated with congenital malformations, microcephaly, intrauterine growth retardation, low birth weight, congenital heart disease, facial dysmorphism and intellectual disability in the unborn child.[42] In our cohort, $67 \%$ of women were of childbearing age and, of them, $44 \%$ had a Phe level above 360 umol/L. For this reason, we are implementing new strategies, such as a specialized clinic, a PKUm protocol, educational workshops and talks to improve adherence and prevent sequelae.

The main objective of proposing a protocol for the diagnosis and monitoring of PKU is to prevent intellectual disability 
in diagnosed individuals and ensure optimal growth and development. In the current analysis, carried out in the active PKU Chilean cohort, we evaluated psychomotor development among children under 4 years of age and obtained the results for 22 subjects between 1 - 3 years and only 1 individual between 6 - 12 months, out of a total of 31 individuals considered in these age groups. We observed an average MDI score of $81.9 \pm 15.8$ which is close to the lower limit of normality ( 80 points).[22]

High levels of Phe alter neurotransmission and brain protein synthesis due to the imbalance of LNAA, with a consequent reduction in serotonin and dopamine synthesis. In addition, there is a structural effect on dendritic arborization, synaptic density, as well as alterations in postnatal myelination in specific areas such as the prefrontal cortex. These changes would explain the alteration in executive functions, attention, emotional and behavioral disorders observed in untreated PKU patients.[43]

In the sub-set of active PKU participants older than 4 years of age, $85 \%$ had a normal IQ (normal range: $80-120$ points), $6 \%$ were classified as borderline (range: 79 - 70 points) and $8 \%$ classified with intellectual disability, mostly in the mild range (range: 69 - 55 points). Supporting this result, when correlating the scores obtained in the cognitive evaluations and blood Phe level we observed a negative association. Therefore, keeping Phe levels under $360 \mathrm{umol} / \mathrm{L}$, avoiding fluctuations, will favor the correct neuropsychological functioning of individuals with PKU.[40,44] More that $80 \%$ of the sample had neuropsychologial functioning within the normal range, likely a result of good Phe level control.

Governments or institutions considering implementing NBS programs for PKU should include a centralized clinical follow-up program, which uses validated protocols, and conducts evaluations according to age. PKU is a chronic pathologies, which will requires maintenance a good lifelong dietary adherence to ensure that patients are actively incorporated into society.[45]

\section{Conclusions}

We know that early diagnosis of PKU reduces the risk of Phe toxicity at the brain level, which prevents intellectual disability. Implementation of the NBS program in Chile in 1992, the subsidizing of the PS without Phe, the creation and publication of the Chilean protocol for the management of PKU, based on more than 30 years of experience and on the protocols published by the United States[5] and the European Union[10,41], have allowed for the monitoring of the Chilean cohort.

Analyses carried out for the period 2010-2020 show us that the NBS program has had little variation in relation to age of diagnosis, allowing early diagnostic confirmation and the start of treatment before one month of life. Overweight/obesity must be addressed in advance to avoid obesity later in life and reduce the risks of triggering diseases such as cardiovascular disease, insulin resistance and diabetes mellitus.
With respect to protein intake, approximately $80 \%$ of the total protein ingested comes from the PS without Phe, therefore, it is vitally important to promote its use at all stages of life.

Eighty percent of the Chilean cohort maintains their medical/ nutritional, metabolic and cognitive follows-up appointments. This is due to the comprehensive and constant education that families and patients with PKU receive by the multidisciplinary team and the commitment acquired by families from the start of treatment.

We emphasize the importance of a reference center, preferably a centralized one, as in Chile, since in this way it is possible to have and apply a protocol in a unified way. In addition, it is fundamental to provide education throughout the life cycle, which is a substantial part of the comprehensive monitoring program carried out by the multidisciplinary team in Chile.

\section{Acknowledgements}

The authors would like to acknowledge the laboratory staff at the Laboratory of Genetics and Metabolic Diseases (LabGEM) of INTA, University of Chile, for their assistance and to all the children and their families for their trust in our staff.

\section{Funding}

The study was not funded by any grant. The study was supported by LabGEM, INTA, University of Chile.

\section{Declaration of Conflicting Interests}

No conflict of interests.

\section{References}

1. Colombo M, Cornejo Espinosa V, Raimann Ballas E, eds. Errores innatos en el metabolismo del niño. 4th ed. Santiago do Chile: Editorial Universitaria; 2017.

2. Blau N, Spronsen FJ van, Levy HL. Phenylketonuria. The Lancet. 2010;376(9750):1417-1427. doi:10.1016/S01406736(10)60961-0

3. Cornejo V, Raimann E, Cabello JF, et al. Past, present and future of newborn screening in Chile. J Inherit Metab Dis. 2010;33(S3):301-306. doi:10.1007/s10545-010-9165-8

4. Singh RH, Rohr F, Frazier D, et al. Recommendations for the nutrition management of phenylalanine hydroxylase deficiency. Genet Med. 2014;16(2):121-131. doi:10.1038/ gim.2013.179

5. Singh RH, Cunningham AC, Mofidi S, et al. Updated, web-based nutrition management guideline for PKU: An evidence and consensus based approach. Mol Genet Metab. 2016;118(2):72-83. doi:10.1016/j.ymgme.2016.04.008 
6. Castro G, Hamilton V, Cornejo V. Chilean nutrition management protocol for patients with phenylketonuria. J Inborn Errors Metab Screen. 2017;5:e160058. doi: $10.1177 / 2326409816689788$

7. Spronsen FJ van, Burgard P. The truth of treating patients with phenylketonuria after childhood: The need for a new guideline. J Inherit Metab Dis. 2008;31(6):673-679. doi:10.1007/s10545-008-0918-6

8. Robert Guthrie AS. A simple phenylalanine method for detecting phenylketonuria in large populations of newborn infants. Pediatrics. 1963;32:338-343.

9. Cornejo V, Manríquez V, Colombo M, et al. Phenylketonuria diagnosed during the neonatal period and breast feeding. Rev Med Chil. 2003;131(11):1280-1287.

10. MacDonald A, van Wegberg AMJ, Ahring K, et al. PKU dietary handbook to accompany PKU guidelines. Orphanet J Rare Dis. 2020;15(1):171. doi:10.1186/s13023-020-01391-y

11. Hofman DL, Champ CL, Lawton CL, Henderson M, Dye L. A systematic review of cognitive functioning in early treated adults with phenylketonuria. Orphanet J Rare Dis. 2018;13(1):150. doi:10.1186/s13023-018-0893-4

12. Anastasoaie V, Kurzius L, Forbes P, Waisbren S. Stability of blood phenylalanine levels and IQ in children with phenylketonuria. Mol Genet Metab. 2008;95(1-2):17-20. doi:10.1016/j.ymgme.2008.06.014

13. Hood A, Grange DK, Christ SE, Steiner R, White DA. Variability in phenylalanine control predicts IQ and executive abilities in children with phenylketonuria. Mol Genet Metab. 2014;111(4):445-451. doi:10.1016/j. ymgme.2014.01.012

14. Lubenow N, Diepenbrock F, Schickling H, Bock D, Heckler $\mathrm{R}$, Sander J. Phenylketonuria screening with a fluorometric microplate assay. Eur J Clin Chem Clin Biochem J Forum Eur Clin Chem Soc. 1994;32(7):525-528. doi:10.1515/ cclm.1994.32.7.525

15. de Onis M, Onyango AW, Borghi E, Siyam A, Nishida C, Siekmann J. Development of a WHO growth reference for school-aged children and adolescents. Bull World Health Organ. 2007;85(9):660-667. doi:10.2471/blt.07.043497

16. WHO Multicentre Growth Reference Study Group. WHO Child Growth Standards based on length/height, weight and age. Acta Paediatr Oslo Nor. 2006;95(S450):76-85. doi:10.1111/j.1651-2227.2006.tb02378.x

17. Ministerio de Salud de Chile. Patrones de crescimento para la evaluación nutricional de niños, niñas y adolescentes, desde el nacimiento hasta los 19 años de edad. Santiago: Ministerio de Salud de Chile; 2017.

18. Salesa Barja, Raquel Burrows, Eduardo Atalah, et al. Norma para la evaluacion nutricional de niños, niñas y adolescentes de 5 años a 19 años de edad. Santiago: Ministerio de Salud de Chile; 2016.
19. World Health Organization. Obesity: preventing and managing the global epidemic: report of a WHO consultation on obesity. Geneva: WHO; 1997.

20. National Institute of Health. Nutrient recommendations: Dietary Reference Intakes (DRI). https://ods.od.nih.gov/ healthinformation/dietary_reference_intakes.aspx

21. Bayley N. Bayley scales of infant development. 2nd ed. San Antonio, US: The Psychological Corporation; 1993.

22. Nellis L, Gridley BE. Review of the Bayley scales of infant development - second edition. J Sch Psychol. 1994;32(2):201209. doi:10.1016/0022-4405(94)90011-6

23. Warschausky S. Wechsler Preschool and Primary Scale of Intelligence. In: Kreutzer JS, DeLuca J, Caplan B, eds. Encyclopedia of Clinical Neuropsychology. New York:Springer; 2011:2690-2693.

24. Woolger C. Wechsler Intelligence Scale for ChildrenThird Edition (wisc-iii). In: Dorfman WI, Hersen M, eds. Understanding Psychological Assessment. Perspectives on Individual Differences. New York, Springer; 2011: 219-233.

25. Saklofske DH, Schoenberg MR. Wechsler adult intelligence scale (all versions). In: Kreutzer JS, DeLuca J, Caplan B, eds. Encyclopedia of Clinical Neuropsychology. New York, Springer; 2011:2675-2680.

26. Chile. Instituto Nacional de Estadísticas. Censo de población y vivienda 2017. Santiago: IEN; 2017.

27. Borrajo GJ. Panorama epidemiológico de la fenilcetonuria (PKU) en Latinoamérica. Acta Pediatr Mexico. 2014;33(6):279-287. https://www.redalyc.org/ pdf/4236/423640339001.pdf

28. Borrajo GJC, Borrajo GJC. Newborn screening for phenylketonuria: Latin American consensus guidelines. J Inborn Errors Metab Screen. 2016;4:e160034. doi:10.1177/2326409816682764

29. SLEIMPN. Late breaking news abstracts. Presentation at 13 th International Congress of Inborn Errors of Metabolism. September 5-8, 2010. Rio de Janeiro, Brazil.

30. Ministerio de Educación de Chile. Junta nacional de auxilio escolar y becas. Mapa Nutricional 2019. Santiago: JUNAEB.

31. Ministerio de Salud de Chile. Encuesta nacional de salud 2016-2017. Departamento de Epidemeología. http://epi. minsal.cl/encuesta-nacional-de-salud-2015-2016/

32. Burton BK, Jones KB, Cederbaum S, et al. Prevalence of comorbid conditions among adult patients diagnosed with phenylketonuria. Mol Genet Metab. 2018;125(3):228-234. doi:10.1016/j.ymgme.2018.09.006

33. Gokmen Ozel H, Ahring K, Bélanger-Quintana A, et al. Overweight and obesity in PKU: The results from 8 centres in Europe and Turkey. Mol Genet Metab Rep. 2014;1:483486. doi:10.1016/j.ymgmr.2014.11.003 
34. Rocha JC, van Rijn M, van Dam E, et al. Weight Management in Phenylketonuria: What Should Be Monitored? Ann Nutr Metab. 2016;68(1):60-65. doi:10.1159/000442304

35. Kose E, Aksoy B, Kuyum P, Tuncer N, Arslan N, Ozturk Y. The Effects of Breastfeeding in Infants With Phenylketonuria. J Pediatr Nurs. 38:27-32. doi:10.1016/j. pedn.2017.10.009

36. Aguiar A, Ahring K, Almeida MF, et al. Practices in prescribing protein substitutes for PKU in Europe: No uniformity of approach. Mol Genet Metab. 2015;115(1):1722. doi:10.1016/j.ymgme.2015.03.006

37. FAO-WHO-UNU. Dietary protein quality evaluation in human nutrition. Report of an FAO expert consultation. 2011, 1-2 April. Auckland, New Zealand. FOA Food and Nutrition Paper 92 (2013).

38. Burton BK, Leviton L. Reaching out to the lost generation of adults with early-treated phenylketonuria (PKU). Mol Genet Metab. 2010;101(2):146-148. doi:10.1016/j. ymgme.2010.06.006

39. Jurecki ER, Cederbaum S, Kopesky J, et al. Adherence to clinic recommendations among patients with phenylketonuria in the United States. Mol Genet Metab. 2017;120(3):190-197. doi:10.1016/j.ymgme.2017.01.001

40. Romani C, Manti F, Nardecchia F, et al. Cognitive outcomes and relationships with phenylalanine in phenylketonuria:
A comparison between italian and english adult samples. Nutrients. 2020;12(10):3033. doi:10.3390/nu12103033.

41. van Wegbergpast AMJ, MacDonald A, Ahring K, et al. The complete European guidelines on phenylketonuria: diagnosis and treatment. Orphanet $J$ Rare Dis. 2017;12(1):162. doi:10.1186/s13023-017-0685-2

42. Prick BW, Hop WC, Duvekot JJ. Maternal phenylketonuria and hyperphenylalaninemia in pregnancy: pregnancy complications and neonatal sequelae in untreated and treated pregnancies. Am J Clin Nutr. 2012;95(2):374-382. doi:10.3945/ajcn.110.009456

43. Ashe K, Kelso W, Farrand S, et al. Psychiatric and Cognitive Aspects of Phenylketonuria: The Limitations of Diet and Promise of New Treatments. Front Psychiatry. 2019;10:561. doi:10.3389/fpsyt.2019.00561

44. de la Parra A, García MI, Hamilton V, Arias C, Cabello JF, Cornejo V. First-year metabolic control guidelines and their impact on future metabolic control and neurocognitive functioning in children with PKU. Mol Genet Metab Rep. 2017;13:90-94. doi:10.1016/j.ymgmr.2017.09.003

45. van Wegberg AMJ, MacDonald A, Abeln D, et al. Patient's thoughts and expectations about centres of expertise for PKU. Orphanet J Rare Dis. 2021;16(1):2. doi:10.1186/ s13023-020-01647-7 